\title{
Predictors of Annual Base Salary for Health Economics, Outcomes Research, and Market Access Professionals in the Biopharmaceutical Industry
}

\author{
Somraj Ghosh, MS; Karen L. Rascati, PhD; Ankit Shah, MS; and Patti Peeples, RPh, PhD
}

\begin{abstract}
BACKGROUND: Analysis of salary data for health economics, outcomes research, and market access professionals in biopharmaceutical space plays an important role in hiring talent, benchmarking remuneration, and evaluating income discrepancies.
\end{abstract}

OBJECTIVES: To (a) identify predictors of annual base salary (ABS) for health economics, outcomes research, and market access professionals who participated in the 2017 Global Salary Survey by HealthEconomics.Com and (b) evaluate salary-related gender disparity among survey respondents.

METHODS: 501 professionals from the HealthEconomics.Com global subscriber list participated in a survey that assessed salary, bonus, benefits, and job satisfaction in June 2017. Two multivariable regression models identified significant predictors of ABS for U.S. and non-U.S. regions separately. Analysis of variance determined interaction effects between gender, organizational size, job title, and people management responsibilities separately.

RESULTS: Of the 501 respondents, 385 were included in the analysis because they reported ABS. Median ABS for male $(n=117)$ and female $(n=111)$ U.S.-based respondents was $\$ 172,500$ and $\$ 162,500$, respectively. For male $(n=75)$ and female $(n=65)$ non-U.S.-based respondents, the median was identical at $\$ 92,500$. Mean (SD) ABS between male $(\$ 180,534$ $[\$ 77,755])$ and female $(\$ 165,113[\$ 64,604] ; \mathrm{t}[226]=1.62 ; P=0.106)$ U.S. respondents was not significantly different. Mean (SD) ABS for male $(\$ 110,900$ [\$65,898]) and female $(\$ 98,039[\$ 48,639] ; t[138]=1.30$; $P=0.196)$ non-U.S. respondents was not significantly different, as well. Multivariable regression models for U.S. and non-U.S. respondents accounted for $62.7 \%$ and $63.9 \%$ of variance in ABS $(P<0.001)$, respectively. In both models, significantly higher salaries were associated with professionals aged $>40$ years; biopharmaceutical employment; having a PhD, PharmD, or MD; and having a job title of president or director (all $P<0.05$ ).

CONCLUSIONS: After controlling for covariates, gender was not statistically significantly associated with ABS. Age, organization type, terminal degree, and job title were significant predictors of higher salaries inside and outside of the United States. Additional research should be conducted to increase generalizability of results, which were based on a convenience sample.

J Manag Care Spec Pharm. 2019;25(12):1328-33

Copyright @ 2019, Academy of Managed Care Pharmacy. All rights reserved.

\section{What is already known about this subject}

Analysis of salary data serves as an effective means to attract and retain top talent and benchmark remunerations and benefits and examine income disparity across groups.

Peer-reviewed analysis of salary data has been published in the past for physicians, pharmacists, and physician assistants.

\section{What this study adds}

Various factors have been shown to be associated with higher salaries, such as years in an organization, residence in the United States, job title, and male sex.

The 2017 salary survey indicated that most factors previously addressed in the literature were found to play a role in salary differences; however, the salary gap between men and women respondents was smaller than previous studies and not statistically significant.

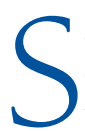
alary surveys collate information in order to characterize compensation, benefits, bonuses, and other remunerationrelated perks and enable benchmarking of remuneration to optimize competitive salary structures., ${ }^{1,2}$ In addition, salary surveys also allow for analytics geared towards attracting, supporting, and retaining employees by the human resources department within organizations. ${ }^{2}$

Publicly available compensation surveys for health economics, outcomes research, and market access (known collectively as HEOR/MA) professionals in the biopharmaceutical and managed care space is necessary yet sparse. Considering the cross-functional nature of the HEOR/MA field and the diversity of the talent pool it attracts, salary surveys play an even more important role in recruiting and retaining top talent, benchmarking remuneration and benefits, and evaluating salary-related gender disparity.

HealthEconomics.Com is a global strategy consulting firm that conducts a biannual employee-reported compensation survey aimed at describing the current conditions of HEOR/ MA employees worldwide. Participants in the survey comprise professionals from biopharmaceutical and medical device organizations, health care consulting firms, managed care organizations, and academia. 
An important function of the survey is to assess if salaryrelated disparities exist. Salary-related gender disparity across industries is well documented. According to a study conducted in 2015 that included internal medicine residency directors, salary disparities cited decades ago still persisted. ${ }^{3}$ In another study that comprised life sciences faculty, significant salary disparities were found between male and female members of the faculty that could not be explained by productivity or other predictors of remuneration. ${ }^{4}$ The study also recommended that policies pertaining to compensation and career progression for women in science should consider adjustments for time spent in childbearing, traditional familial responsibilities, pay-related historical practices, and persisting sexist attitudes. Several studies have also reported salary-related gender disparity among pharmacists, physician assistants, and other science-driven professions. ${ }^{5,6} \mathrm{~A}$ recent publication evaluated the 2015 HealthEconomics.com survey results and found differences in annual base salary (ABS) by gender and geography (United States vs. non-United States). ${ }^{7}$ Thus, the objectives of this updated analysis were to (a) determine the significant predictors of ABS for HEOR/MA professionals employed in the biopharmaceutical, health care consulting, and managed care industries, along with academia, who participated in the 2017 Global Salary Survey administered by HealthEconomics.Com and (b) evaluate salary-related gender disparity among the survey respondents.

\section{Methods}

HealthEconomics.Com administers a biannual salary survey that assembles information on salary, bonuses, benefits, job satisfaction, and success at work for HEOR/MA professionals. The survey for the current analysis was conducted from January to April 2017 using an online survey service. Invitation to participate in the survey was conveyed via email to subscribers of the HealthEconomics.Com active global distribution list, along with website announcements and notifications on relevant social media platforms. The HealthEconomics.Com subscriber sample consists of 24,800 global HEOR/MA real-world evidence professionals in biopharma, medical device, consulting, health technology assessment, or private insurance organizations. A total of $501 \mathrm{HEOR/MA}$ professionals participated in the survey. Of the 501 respondents, 385 were considered for the final analysis after excluding respondents who did not report $\mathrm{ABS}$. At the time of the survey, respondents were employed in the pharmaceutical, biotechnology, managed care, and health care consulting industries. A small minority of respondents comprised academicians who also took the survey.

\section{Data Collection}

The survey items focused on demographic characteristics, including age (in years), gender, race, marital status, education, native language, country of residence, and English fluency.
ABS excluding benefits and bonuses was reported in U.S. dollars. In addition, the survey items also collected information on bonuses, benefits, yearly raises, years of work experience, organizational size, job titles, budget management responsibility, and hiring authority.

\section{Data Analysis}

Standard descriptive statistics were conducted to summarize demographic characteristics of the survey responses. Two separate multivariable linear regression models were developed to identify significant predictors of ABS for U.S.- and non-U.S.based professionals. In both models, the outcome variable was ABS, which was categorized in increments of $\$ 5,000$, with the midpoint of each increment used to represent an estimate of the salary. Age, gender, race, marital status, type of employer, level of education, native language, fluency in spoken English, hiring authority, budget management responsibilities, organizational size, and job title were incorporated as predictor variables to fit the model. Also, an analysis of variance (ANOVA) model was developed to determine the interaction effects between gender, organizational size, job title, and people management responsibilities separately.

\section{Results}

\section{Demographic Characteristics}

Of the total surveys sent out, 385 responses were considered for the analysis. A detailed description of the demographic characteristics of the respondents is included in Table 1. The median base salary for male and female respondents based in the United States was $\$ 172,500$ and $\$ 162,500$. For male and female respondents based outside of the United States, the median base salary was identical at $\$ 92,500$. There was no statistically significant difference in mean (standard deviation [SD]) salary between male $(\$ 180,534[\$ 77,755])$ and female $(\$ 165,113[\$ 64,604 ; \mathrm{t}[226]=1.62 ; P=0.106)$ respondents based in the United States. Similarly, for respondents based outside of the United States, there was no statistically significant difference in mean (SD) salary for males $(\$ 110,900[\$ 65,898])$ and females ( $\$ 98,039$ [\$48,639]; $[138]=1.30 ; P=0.196)$.

We also computed male and female base salaries stratified by job titles (chief executive officer/senior vice president/vice president, director/associate director, manager, and academic) for respondents located within and outside of the United States separately (Table 1). Again, while there were differences between male and female salaries, the difference was not found to be statistically significant.

\section{Predictors of Annual Base Salary}

Two multivariable linear regression models were developed to identify key predictors of ABS for respondents residing inside and outside of the United States. The model representing U.S.based respondents explained $62.7 \%(P \leq 0.001)$ of the variance, 


\section{Predictors of Annual Base Salary for Health Economics, Outcomes Research, and Market Access Professionals in the Biopharmaceutical Industry}

\section{TABLE 1 Demographic Characteristics of HEOR/MA Professionals in Non-U.S. and U.S. Regions}

\begin{tabular}{|c|c|c|c|c|c|c|}
\hline Variable & $\begin{array}{c}\text { Non-U.S. } \\
\text { Professionals } \\
\mathrm{n}=142(100 \%)\end{array}$ & $\begin{array}{c}\text { Non-U.S. } \\
\text { Salary, \$ } \\
\text { Mean (SD) }\end{array}$ & $\begin{array}{c}\text { Non-U.S. } \\
\text { Salary, \$ } \\
\text { Median }\end{array}$ & $\begin{array}{c}\text { U.S. } \\
\text { Professionals } \\
\mathrm{n}=232(100 \%)\end{array}$ & $\begin{array}{c}\text { U.S. } \\
\text { Salary, \$ } \\
\text { Mean (SD) }\end{array}$ & $\begin{array}{c}\text { U.S. } \\
\text { Salary, \$ } \\
\text { Median }\end{array}$ \\
\hline \multicolumn{7}{|l|}{ Age, year } \\
\hline $21-30$ & $25 \quad(17.6)$ & $53,600 \quad(8,071)$ & 50,000 & $21 \quad(9.1)$ & $101,905 \quad(46,950)$ & 97,500 \\
\hline $31-40$ & $54(38.0)$ & $87,269 \quad(38,079)$ & 82,500 & $79(34.4)$ & $157,184 \quad(59,674)$ & 142,500 \\
\hline $41-50$ & $42 \quad(29.6)$ & $142,798 \quad(68,097)$ & 135,000 & $72(31.3)$ & $194,618 \quad(75,747)$ & 185,000 \\
\hline$>50$ & $21 \quad(14.8)$ & $137,738 \quad(53,367)$ & 137,500 & $58 \quad(25.2)$ & $194,052 \quad(68,998)$ & 192,500 \\
\hline Missing & $0 \quad(0.0)$ & & & $2(0.8)$ & & \\
\hline \multicolumn{7}{|l|}{ Gender } \\
\hline Male & $75 \quad(53.6)$ & $110,900 \quad(65,898)$ & 92,500 & $117(51.3)$ & $180,534 \quad(77,755)$ & 172,500 \\
\hline Female & $65(46.4)$ & $98,038 \quad(48,639)$ & 92,500 & $111(48.7)$ & $165,113 \quad(64,604)$ & 162,500 \\
\hline Missing & $2 \quad(1.4)$ & & & $4 \quad(1.7)$ & & \\
\hline \multicolumn{7}{|l|}{ Race } \\
\hline White & $89 \quad(63.6)$ & $117,837 \quad(58,634)$ & 102,500 & $150(65.8)$ & $177,200 \quad(68,252)$ & 172,500 \\
\hline Black/other & $12 \quad(8.6)$ & $95,833 \quad(63,589)$ & 66,250 & $25(11.0)$ & $147,600 \quad(71,605)$ & 137,500 \\
\hline Asian & $34 \quad(24.3)$ & $78,750 \quad(53,194)$ & 50,000 & $47(20.6)$ & $152,926 \quad(67,872)$ & 147,500 \\
\hline Pacific Islander/Nativeb & $5 \quad(3.6)$ & $72,500 \quad(33,726)$ & 57,500 & $6 \quad(2.6)$ & $246,250 \quad(51,424)$ & 247,500 \\
\hline Missing & $2 \quad(1.4)$ & & & $4 \quad(1.7)$ & & \\
\hline \multicolumn{7}{|l|}{ Marital status } \\
\hline Single & $33 \quad(24.3)$ & $79,924 \quad(42,045)$ & 57,500 & $41 \quad(18.2)$ & $142,317 \quad(69,456)$ & 132,500 \\
\hline Married & $85 \quad(62.5)$ & $107,618 \quad(58,677)$ & 97,500 & $163(72.4)$ & $180,844 \quad(69,052)$ & 172,500 \\
\hline Other & $18 \quad(13.2)$ & $122,083 \quad(73,341)$ & 97,500 & $21 \quad(9.3)$ & $159,643 \quad(71,791)$ & 157,500 \\
\hline Missing & $6 \quad(4.2)$ & & & $7 \quad(3.0)$ & & \\
\hline \multicolumn{7}{|l|}{ Employer } \\
\hline Pharma & $86 \quad(60.1)$ & $123,459 \quad(62,470)$ & 107,500 & $120(51.7)$ & $196,083 \quad(62,722)$ & 187,500 \\
\hline Consulting & $37(26.1)$ & $82,162 \quad(43,875)$ & 57,500 & $61(26.3)$ & $162,664 \quad(86,916)$ & 142,500 \\
\hline Managed Care & $9 \quad(6.3)$ & $77,778 \quad(34,987)$ & 67,500 & $25(10.8)$ & $133,700 \quad(59,517)$ & 132,500 \\
\hline Academia & $3 \quad(2.1)$ & $\mathrm{NR}^{\mathrm{a}}$ & $\mathrm{NR}^{\mathrm{a}}$ & $12 \quad(5.2)$ & $120,208 \quad(44,536)$ & 117,500 \\
\hline Other & $\begin{array}{ll}7 & (4.9) \\
\end{array}$ & $62,143 \quad(22,473)$ & 50,000 & $14 \quad(6.0)$ & $142,857 \quad(50,209)$ & 147,500 \\
\hline Missing & $0 \quad(0.0)$ & & & & & \\
\hline \multicolumn{7}{|l|}{ Highest degree } \\
\hline Bachelors & $14 \quad(9.9)$ & $101,071 \quad(58,799)$ & 90,000 & $22 \quad(9.5)$ & $182,841 \quad(87,544)$ & 182,500 \\
\hline Masters & $70 \quad(49.3)$ & $92,964 \quad(45,660)$ & 82,500 & $92(39.8)$ & $168,967 \quad(78,178)$ & 152,500 \\
\hline PhD/MD/PharmD & $50 \quad(35.2)$ & $128,500 \quad(69,622)$ & 115,000 & $113(48.9)$ & $178,739 \quad(63,361)$ & 172,500 \\
\hline Other & $8 \quad(5.6)$ & $74,375 \quad(52,453)$ & 50,000 & $4 \quad(1.7)$ & $\mathrm{NR}^{\mathrm{a}}$ & $\mathrm{NR}^{\mathrm{a}}$ \\
\hline Missing & $0 \quad(0.0)$ & & & $1 \quad(0.4)$ & & \\
\hline \multicolumn{7}{|l|}{ Native language } \\
\hline English & $45 \quad(31.7)$ & $119,444 \quad(58,436)$ & 102,500 & $185(80.8)$ & $176,716 \quad(71,646)$ & 172,500 \\
\hline Other & $97 \quad(68.3)$ & $98,634 \quad(58,405)$ & 77,500 & $44(19.2)$ & $164,716 \quad(75,635)$ & 142,500 \\
\hline Missing & $11 \quad(7.7)$ & & & $3 \quad(1.3)$ & & \\
\hline \multicolumn{7}{|l|}{ English fluency } \\
\hline Limited/working & $5 \quad(3.5)$ & $96,000 \quad(63,211)$ & 50,000 & $3 \quad(1.3)$ & $\mathrm{NR}^{\mathrm{a}}$ & $\mathrm{NR}^{\mathrm{a}}$ \\
\hline Professional & $88 \quad(62.0)$ & $94,091 \quad(54,640)$ & 67,500 & 75 (32.6) & $163,300 \quad(71,102)$ & 142,500 \\
\hline Nativeb/bilingual & $49(34.5)$ & $126,173 \quad(61,657)$ & 107,500 & $152(66.1)$ & $179,589 \quad(73,303)$ & 172,500 \\
\hline Missing & $0 \quad(0.0)$ & & & $2 \quad(0.8)$ & & \\
\hline \multicolumn{7}{|l|}{ Hiring authority } \\
\hline Yes & $53 \quad(37.6)$ & $136,604 \quad(66,347)$ & 132,500 & $103(45.0)$ & $217,500 \quad(74,978)$ & 217,500 \\
\hline No & $88 \quad(62.4)$ & $86,477 \quad(45,341)$ & 67,500 & $126(55.0)$ & $138,988 \quad(46,311)$ & 137,500 \\
\hline Missing & $1 \quad(0.7)$ & & & $3 \quad(1.3)$ & & \\
\hline \multicolumn{7}{|l|}{ Budget management } \\
\hline Yes & $76 \quad(53.5)$ & $132,007 \quad(61,617)$ & 125,000 & $145(63.3)$ & $196,913 \quad(73,866)$ & 187,500 \\
\hline No & $66 \quad(46.5)$ & $74,393 \quad(61,617)$ & 52,500 & $84(36.7)$ & $135,268 \quad(49,458)$ & 132,500 \\
\hline Missing & $12 \quad(8.5)$ & & & $3 \quad(1.3)$ & & \\
\hline
\end{tabular}


Predictors of Annual Base Salary for Health Economics, Outcomes Research, and Market Access Professionals in the Biopharmaceutical Industry

TABLE 1 Demographic Characteristics of HEOR/MA Professionals in Non-U.S. and U.S. Regions (continued)

\begin{tabular}{|c|c|c|c|c|c|c|}
\hline Variable & $\begin{array}{c}\text { Non-U.S. } \\
\text { Professionals } \\
\mathrm{n}=142(100 \%)\end{array}$ & $\begin{array}{c}\text { Non-U.S. } \\
\text { Salary, \$ } \\
\text { Mean (SD) }\end{array}$ & $\begin{array}{l}\text { Non-U.S. } \\
\text { Salary, \$ } \\
\text { Median }\end{array}$ & $\begin{array}{c}\text { U.S. } \\
\text { Professionals } \\
\mathrm{n}=232(100 \%)\end{array}$ & $\begin{array}{c}\text { U.S. } \\
\text { Salary, \$ } \\
\text { Mean (SD) }\end{array}$ & $\begin{array}{c}\text { U.S. } \\
\text { Salary, \$ } \\
\text { Median }\end{array}$ \\
\hline \multicolumn{7}{|l|}{ Organizational size } \\
\hline $1-1,000$ & $66 \quad(46.8)$ & $88,220 \quad(50,647)$ & 60,000 & $92(40.5)$ & $160,353 \quad(83,921)$ & 147,500 \\
\hline $1,001-5,000$ & $13 \quad(9.2)$ & $93,846 \quad(43,176)$ & 82,500 & $26(11.5)$ & $176,058 \quad(73,686)$ & 147,500 \\
\hline$>5,000$ & $62(44.0)$ & $124,718 \quad(64,494)$ & 115,000 & $109(48.0)$ & $186,376 \quad(59,414)$ & 177,500 \\
\hline Missing & $1 \quad(0.7)$ & & & $5 \quad(2.2)$ & & \\
\hline \multicolumn{7}{|l|}{ Job title } \\
\hline CEO/SVP/VP & $14 \quad(9.9)$ & $170,000 \quad(75,294)$ & 167,500 & $49(21.1)$ & $246,429 \quad(79,363)$ & 242,500 \\
\hline Director/associate director & $51 \quad(35.9)$ & $138,873 \quad(54,907)$ & 132,500 & $102(44.0)$ & $179,485 \quad(52,079)$ & 177,500 \\
\hline Manager & $73 \quad(51.4)$ & $72,329 \quad(28,606)$ & 57,500 & $64 \quad(27.6)$ & $123,516 \quad(45,617)$ & 125,000 \\
\hline Academic & $4 \quad(2.8)$ & $\mathrm{NR}^{\mathrm{a}}$ & $\mathrm{NR}^{\mathrm{a}}$ & $17 \quad(7.3)$ & $114,706 \quad(40,251)$ & 117,500 \\
\hline Missing & $0 \quad(0.0)$ & & & $0 \quad(0.0)$ & & \\
\hline \multicolumn{7}{|c|}{$\begin{array}{l}\text { Note: Percentages do not add to } 100 \% \text { due to rounding. } \\
{ }^{a} \text { Mean and median were not reported when cell size was }<5 \text {. } \\
{ }^{b} \text { Native = Native American. } \\
C E O=\text { chief executive officer; HEOR/MA = health economics, outcomes research, and market access; } M D=\text { medical doctor degree; NR=not reported; PharmD = doctor of } \\
\text { pharmacy degree; } P h D=\text { doctor of philosophy degree; } S D=\text { standard deviation; } S V P=\text { senior vice president; } V P=\text { vice president. }\end{array}$} \\
\hline
\end{tabular}

while the model that considered only non-U.S. respondents explained $63.9 \%(P \leq 0.001)$ of the variance in ABS. In both models, significantly higher salaries were associated with professionals aged $>40$ years; biopharmaceutical employment; having a PhD, PharmD, or MD; and having a job title of president or director (all $P<0.05$ ). While hiring authority was a significant predictor in the United States $(P<0.001)$, it was not for respondents based outside the United States $(P=0.810)$. In addition, gender was not a significant predictor of $A B S$ in either model. Parameter estimates for both models are reported in Table 2.

\section{Determining Interaction Effects to Evaluate Gender Disparity in Annual Base Salary}

Two-way ANOVA was conducted to compare the interaction effects of gender and (a) organizational size, (b) current designation, and (c) people management responsibilities separately on ABS of respondents residing inside and outside of the United States. Interaction effects including gender and organizational size $(F[2,218]=0.29, P=0.747)$; gender and job title ( $F[3,220]=0.89, P=0.448)$; and gender and people management responsibilities $(F[3,216]=0.62, P=0.604$ ) were not statistically significant for respondents residing in the United States. Similarly, for non-U.S. respondents, interaction between gender and organizational size $(F[2,133]=0.21, P=0.815)$; gender and job title $(F[2,133]=0.21, P=0.815)$; and gender and people management responsibilities $(F[1,133]=0.27, P=0.602)$ were also not statistically significant.

\section{Discussion}

Mean and median salaries differed by most of the expected factors, such as professionals aged $>40$ years; biopharmaceutical employment; having budget management authority; having hiring authority; having a PhD, PharmD, or MD degree; residing in the United States; working in organizations with $>5,000$ employees; and with a job title of president or director.

Salary disparity between genders in the health care sector have been previously reported., Studies have consistently found a statistically significant difference in remuneration between male and female professionals, with male professionals earning more than their female counterparts. In a study using national data for health care professionals by Seabury et al. (2013), results indicated a significant salary inequality between genders, with a lack of improvement in the gap over time. ${ }^{8}$ The study also noted that overall salary-related gender gap occurred less for nurses and pharmacists as opposed to physicians and other health sector professionals.

While studies have explored gender-related salary disparities for professionals, such as physicians, pharmacists, and physician assistants, $, 3,5,6$ our study explored ABS data for HEOR/MA professionals working in biopharmaceutical, health care consulting, and managed care organizations, along with academia, who constitute an important intellectual asset within the drug development space. An analysis of earlier responses (2015) to this same survey found a statistically significant difference between male and female respondents. ${ }^{7}$ This analysis noted that female respondents reported mean salaries of $\$ 30,000$ lower than males in the United States and $\$ 13,000$ lower for non-U.S. respondents, and differences were statistically different. 


\section{Predictors of Annual Base Salary for Health Economics, Outcomes Research, and Market Access Professionals in the Biopharmaceutical Industry}

TABLE 2 Predictors of Annual Base Salary in Non-U.S. and U.S. Regions

\begin{tabular}{|c|c|c|c|c|c|}
\hline Variable & Reference & $\begin{array}{c}\text { Parameter Estimate } \\
(\text { Non-U.S. })^{\mathrm{a}}\end{array}$ & $\begin{array}{c}\text { P Value } \\
\text { (Non-U.S.) }\end{array}$ & $\begin{array}{c}\text { Parameter Estimate } \\
\text { (U.S.) }\end{array}$ & $\begin{array}{l}\text { P Value } \\
\text { (U.S.) }\end{array}$ \\
\hline \multicolumn{6}{|l|}{ Age, years } \\
\hline $21-30$ & \multirow{3}{*}{$31-40$} & $-7,171$ & 0.486 & $-13,478$ & 0.264 \\
\hline $41-50$ & & 28,394 & $<0.001^{b}$ & 22,716 & $0.003^{b}$ \\
\hline$>50$ & & 33,158 & $0.002^{b}$ & 22,856 & $0.007^{b}$ \\
\hline \multicolumn{6}{|l|}{ Gender } \\
\hline Female & Male & $-8,788$ & 0.209 & $-3,772$ & 0.536 \\
\hline \multicolumn{6}{|l|}{ Race } \\
\hline Black/Latino & \multirow{3}{*}{ White } & $-9,855$ & 0.437 & $-7,328$ & 0.489 \\
\hline Asian & & $-3,616$ & 0.693 & $-10,014$ & 0.244 \\
\hline Other & & $-20,090$ & 0.252 & $-25,979$ & 0.187 \\
\hline \multicolumn{6}{|l|}{ Employer } \\
\hline Consulting & \multirow{4}{*}{ Pharma } & $-20,868$ & $0.039^{b}$ & $-40,126$ & $<0.001^{b}$ \\
\hline Managed care & & $-62,173$ & $<0.001^{\mathrm{b}}$ & $-46,916$ & $<0.001^{b}$ \\
\hline Academia & & $-7,337$ & 0.811 & $-38,389$ & $0.005^{\mathrm{b}}$ \\
\hline Other & & $-36,709$ & $0.035^{b}$ & $-100,619$ & $<0.001^{b}$ \\
\hline \multicolumn{6}{|l|}{ Education } \\
\hline Bachelors & \multirow{3}{*}{$\mathrm{PhD} / \mathrm{MD} / \mathrm{Ph}$ armD } & $-7,281$ & 0.547 & $-10,651$ & $0.002^{b}$ \\
\hline Masters & & $-20,072$ & $0.006^{\mathrm{b}}$ & $-18,014$ & $0.006^{\mathrm{b}}$ \\
\hline Other & & $-33,190$ & $0.027 \mathrm{~b}$ & $-34,337$ & $0.005^{b}$ \\
\hline \multicolumn{6}{|l|}{ Native language } \\
\hline English & Other & $-7,254$ & 0.530 & $-1,842$ & 0.832 \\
\hline \multicolumn{6}{|l|}{ English fluency } \\
\hline Limited/working & \multirow{2}{*}{ Native/Bilingual } & 21,812 & 0.317 & 14,961 & 0.585 \\
\hline Professional & & $-22,040$ & 0.052 & $-4,861$ & 0.486 \\
\hline \multicolumn{6}{|l|}{ Hiring authority } \\
\hline Yes & No & $-1,968$ & 0.810 & 26,937 & $<0.001^{b}$ \\
\hline \multicolumn{6}{|l|}{ Budget management } \\
\hline Yes & No & 8,810 & 0.288 & 7,319 & 0.342 \\
\hline \multicolumn{6}{|l|}{ Organizational size } \\
\hline$<1,000$ & \multirow{2}{*}{$>5,000$} & $-14,196$ & 0.097 & -7182 & 0.393 \\
\hline $1,001-5,000$ & & $-27,253$ & 0.023 & $-5,202$ & 0.427 \\
\hline \multicolumn{6}{|l|}{ Job title } \\
\hline President/vice president & \multirow{3}{*}{$\begin{array}{c}\text { Director/associate } \\
\text { director }\end{array}$} & 29,227 & $0.019^{b}$ & 75,550 & $<0.001^{\mathrm{b}}$ \\
\hline Manager & & $-39,671$ & $<0.001^{\mathrm{b}}$ & $-20,660$ & $0.017^{b}$ \\
\hline Academic & & $-73,213$ & $0.006^{\mathrm{b}}$ & $-34,642$ & $0.036^{\mathrm{b}}$ \\
\hline
\end{tabular}

Note: Adjusted $R^{2}$ for only U.S. cases model $=62.7 \%$; adjusted $R^{2}$ for only non-U.S. cases model $=63.9 \%$.

aParameter estimates were rounded up or rounded down to the closest whole number.

bSignificance at $P<0.05$.

$\mathrm{MD}=$ medical doctor degree; $P$ harm $\mathrm{D}=$ doctor of pharmacy degree; $\mathrm{PhD}=$ doctor of philosophy degree.

We found a lower mean gap ( $\$ 15,000$ for U.S. respondents and $\$ 12,000$ for non-U.S. respondents), and although these results were in the same direction, these differences were not statistically different before or after adjusting for covariates. In addition, our study also examined the interaction effects of gender, organizational size, current designation, and people management responsibilities (separately) on ABS. Again, contrary to previous research, the interaction effects were not found to be statistically significant.

We hypothesize 3 reasons that could potentially be responsible for such an observation. First, HEOR/MA is a niche field with a relatively smaller work force compared with other specialties involved in drug development. Because of the niche nature of the specialization and a work force that is characterized by significant uniformity in the level of academic qualification, the remuneration package may be structured in a way that leaves little room for disparity. Second, the remuneration is primarily based on academic qualifications and length of work experience that drives a standardized salary structure that, in turn, allows for consistency. Third, a smaller workforce enables better networking, which may indirectly lead to standardization of the salary structure based on analogy and precedence during salary-related negotiations. 


\section{Predictors of Annual Base Salary for Health Economics, Outcomes Research, and Market Access Professionals in the Biopharmaceutical Industry}

\section{Limitations}

This study had multiple limitations. First, the survey data were self-reported, which could potentially lead to a reporting bias. Second, the data were collected from a convenience sample, so it may lack generalizability, especially with respect to countryspecific data outside of the United States. Geographic differences within the United States were not tested, and sample sizes of some variables dictated the collapsing of responses (e.g., highest degree, level of job). Finally, the survey was not validated for accuracy with the individual respondent's employers.

\section{Conclusions}

This study offers updated information about the remuneration structure for HEOR/MA professionals. Most factors associated with a higher salary mirror previous research, with the exception of gender. Both multivariable regression models found that higher salaries were associated with professionals aged $>40$ years; biopharmaceutical employment; having a $\mathrm{PhD}$, PharmD, or MD; and having a job title of president or director (all $P<0.05$ ). Hiring authority was associated with higher salaries in the United States $(P<0.001)$; however, for non-U.S. respondents it was not significantly associated $(P=0.810)$. Also, gender was not a significant predictor of ABS in either model. Future work will include elucidating trends over time regarding HEOR/MA salaries, in particular if gender-based equity continues to be reported.

\section{Authors}

SOMRAJ GHOSH, MS, and KAREN L. RASCATI, PhD, Division of Health Outcomes, College of Pharmacy, University of Texas at Austin. ANKIT SHAH, MS, and PATTI PEEPLES, RPh, PhD, HealthEconomics.Com, Jacksonville, Florida.

AUTHOR CORRESPONDENCE: Karen L. Rascati, PhD, Professor, Division of Health Outcomes, College of Pharmacy, University of Texas at Austin, 1 University Station - A1930, Austin, TX 78712-0127. Tel.: 512.471.1637; E-mail:krascati@mail.utexas.edu.

\section{DISCLOSURES}

No funding supported this research. Shah and Peeples are employed by HealthEconomics.Com, which administered the survey used in this study. The authors report no other potential conflicts of interest.

\section{REFERENCES}

1. HR-Survey.com. Salary/compensation surveys. Retrieved October 18 2018. Available at: https://www.hr-guide.com/Compensation/Salary_ Surveys.htm. Accessed October 19, 2019.

2. Sosnowski S. The importance of benchmarked compensation data. January 23, 2018. Available at: https://www.aseonline.org/News/ Articles/ArtMID/628/ArticleID/1378/The-Importance-of-BenchmarkedCompensation-Data. Accessed November 1, 2019

3. Willett LL, Halvorsen AJ, Furman SM, et al. Gender differences in salary of internal medicine residency directors: a national survey. Asm J Med. 2015;128(6):659-65.

4. DesRoches CM, Zinner DE, Rao SR, et al. Activities, productivity, and compensation of men and women in the life sciences. Acad Med. 2010;85(4):631-39.

5. Brown LM, Schommer JC, Mott D, et al. Examining gender salary disparities: an analysis of the 2003 multistate salary survey. Res Social Adm Pharm. 2006:2(3):370-87

6. Coplan B, Essary AC, Virden TB, et al. Salary discrepancies between practicing male and female physician assistants. Women's Health Issues. 2012;22(1):e83-e89.

7. Carvajal MJ, Peeples P, Popovici I. A probe into the wages and salaries of health economics, outcomes research, and market access professionals. Appl Health Econ Health Policy. 2019;17(5):741-51.

8. Seabury SA, Chandra A, Jena AB. Trends in the earnings of male and female health care professionals in the US, 1987-2010. JAMA Intern Med. 2013;173(18):1748-50. 